\title{
A FRAMEWORK FOR HOMOGENIZING POLY-CRYSTALLINE SILICON WAFERS INCLUDING PRE-CRACKS
}

\author{
$\underline{\text { M. Tariq }}{ }^{1 *}$, C. Gerendt ${ }^{1}$, S. Scheffler ${ }^{1}$, R. Rolfes ${ }^{1}$ \\ ${ }^{1}$ Institute of Structural Analysis (ISD), Leibniz University Hannover, Germany \\ *m.tariq@isd.uni-hannover.de
}

The Photovoltaic (PV) modules are being utilized in novel and diverse ways in recent years. Many experimental investigations are under development in which they are being designed to be applied in extreme environments, e.g. on the wing surface of aircrafts [1] or on the facets of building [2]. During these applications, PV modules undergo high wind loads. A PV module consists of several solar cells. The most critical component of a solar cell is the brittle polycrystalline silicon wafer, which is prone to fracture even under moderate loads. The microcracks in a silicon wafer deteriorate the capability of the solar cell reducing the production of the electric current. The numerical analysis of the extent of such micro-cracks (at the crystal level) in silicon wafers is, therefore, crucial to assess the potential electric yield of the PV modules but also computationally expensive due to the high degree of anisotropy.

In order to reduce the computational costs, solar cells can be homogenized using effective material properties of the representative volume element (RVE). By such a homogenization approach, the degrees of freedom are reduced significantly, yielding a reduced-order model of the PV modules [3]. Some methodologies were already proposed to determine such effective material properties successfully for composite plates or laminas [4]. In this contribution, a virtual framework is developed that incorporates these homogenization techniques in combination with the finite element methods in ABAQUS/Implicit for efficient numerical assessment of the PV module.

The framework homogenizes the elastic material properties of the polycrystalline microstructure, as well as trans/intra-granular fracture for a complete silicon cell. The homogenization of fracture subsequently yields damage parameters for the homogenized solar cell. As a result, the framework provides a good basis for an accurate and computationally efficient representation of the progressive failure in solar cells.

\section{References}

[1] H. Ross (2008) Fly around the World with a Solar Powered Airplane. American Institute of Aeronautics and Astronautics, 32(4), 122-132.

[2] Amoah B.O. Kwame et al. (2020) A Multi-Facet Retrofit Approach to Improve Energy Efficiency of Existing Class of Single-Family Residential Buildings in Hot-Humid Climate Zones. Energies, 5(13).

[3] J. Oliver et al. (2017) Reduced order modeling strategies for computational multiscale fracture. Computer methods in applied mechanics and engineering, 313, 560-595.

[4] C. Sun and S. Li (1988) Three-Dimensional Effective Elastic Constants for Thick Laminates. Journal of Composite materials, 22, 629-639. 